\title{
LA LENGUA DEL BOXEO. PROCEDIMIENTOS DE FORMACIÓN LÉXICA
}

\section{THE LANGUAGE OF BOXING. LEXICAL FORMATION PROCESSES}

\author{
Clara Ayuso Collantes \\ Universidad Pontificia de Comillas \\ claraa.collantes@gmail.com
}

Recibido: $19 / 10 / 2017$

Aceptado: 09/05/2018

\section{Resumen}

El boxeo es un deporte foráneo que se introdujo en España a finales del XIX y principios del XX siguiendo modelos ingleses, sobre todo, $\mathrm{y}$ franceses, de los que primordialmente tomó el lenguaje. De cómo nace, penetra, se adapta, se crea y se expande este lenguaje en el castellano, en sus distintos niveles y con distintos procedimientos, trata este artículo. Para ello se hace un repaso descriptivo a los modos de formación neológica más comunes de que hace gala, tanto a sus componentes léxicos, en la que entrarían los préstamos y adaptaciones, los calcos y las creaciones propias, como a los morfológicos, con formas de derivación y composición, así como a los morfosintácticas: locuciones y elipsis, y a los de inspiración semántica: metáforas y metonimias.

PALABRAS CLAVE: lengua del boxeo; lenguas específicas; neologismos; préstamos; formación léxica.

\begin{abstract}
Boxing is a foreign sport introduced in Spain at end of the $19^{\text {th }}$ century, especially following English and French models, from which Sapnish took the lexicon. This article addresses how this language was born, how it entered, how it was adapted, created and expanded in Spanish, in its different levels and with diverse proceedings. For that purpose we will run through the most common ways of neological formation it shows, both its lexical components, where we can find loanwords and adaptations, calques and its own creations, and its morphological components, with derivative and composed words, as well as the morphosyntactic ones: locutions and ellipses, and those of semantic inspiration: metaphors and metonymies.

KEYWORDS: boxing lexicon; specific languages; neologisms; loanwords; lexical formation.
\end{abstract}

Para citar este artículo / To cite this article: Ayuso, Clara (2018). La lengua del boxeo. Procedimientos de formación léxica. ELUA, 32: 9-31. doi: 10.14198/ELUA2018.32.1

Enlace / Link: http://dx.doi.org/10.14198/ELUA2018.32.1 


\section{EL BOXEO EN ESPAÑA: AUGE Y DECLIVE DE UN DEPORTE POLÉMICO}

El boxeo es un deporte que actualmente no goza de simpatías ni de apoyos en España. Está poco menos que silenciado en los periódicos, y no existe para la televisión ${ }^{1}$. Pero no siempre fue así, pues en los años sesenta y setenta del siglo pasado gozó en España de un gran predicamento y los combates de sus púgiles más brillantes -los Folledo, Durán, Legrá, Carrasco, Velázquez, Ortiz, y el fenómeno Urtain- levantaban pasiones y gran expectación. Sus peleas se televisaban a horas punta y ocupaban las primeras páginas de los periódicos. A un combate podían asistir varios ministros y grandes personalidades del régimen, pues el franquismo veía este deporte con muy buenos ojos y lo promocionaba.

Con la llegada de la democracia las cosas cambiaron ${ }^{2}$. Con ocasión de la muerte del púgil Rubio Melero a consecuencia de los golpes sufridos en un combate celebrado días antes, El País (22-II-1978) lanzó un duro editorial, cuyo título lo decía todo "Contra el boxeo "profesional"”, y en el que se leían razones como estas:

Los reglamentos del marqués de Queensberry no han civilizado esta lucha entre hombres que a la postre sólo tiene por mejor y más celebrado objetivo la pérdida del conocimiento del contrincante. Por esta característica este debería ser el deporte más protegido de injerencias comerciales y crematísticas. Sin embargo, el boxeo profesional ha sido prácticamente absorbido por intereses ajenos al deporte en medida inigualable.

En ese período de la transición democrática se puede creer que este diario fue el abanderado de la lucha contra el turbio mundo del boxeo profesional ${ }^{3}$. Sin embargo, ya en los años del gran auge de este deporte en la época franquista, algunos otros periódicos catalanes como Diario de Barcelona y El Correo Catalán no se arredraban a la hora de manifestar su postura crítica en contra del mismo.

La polémica sobre el valor y la conveniencia social de este deporte, existió, de hecho, desde su aparición en España. Importado de Inglaterra, en donde se había iniciado a principios del siglo XVIII y a mediados del XIX se había regulado con el célebre reglamento del duque de Queensberry, que es el que lo convirtió en el deporte moderno que hoy se conoce, en esa segunda mitad del XIX se popularizó también en Estados Unidos y en Francia $^{5}$. A principios del siglo XX en España tan solo se practicaba en algunos gimnasios de Madrid y Barcelona (Viada, 1903: 689) y fue despuntando tímidamente, según se puede

1 Aunque dicen que está subiendo el número de los que se apuntan al gimnasio para practicarlo como ejercicio físico, y que, en contra de lo que ha ocurrido siempre, que ha sido una práctica de gente sin recursos, son los jóvenes de las clases acomodadas los que ahora se ejercitan en él.

2 El desarrollo del boxeo en España y las causas del cambio de consideración de este deporte en la sociedad española con la democracia vienen analizadas en Sánchez García (2009).

3 Lo haría desde sus inicios en 1976, negándole categoría y espacio. Es muy elocuente el reportaje realizado por el periodista deportivo Julio César Iglesias el 17 de noviembre de 1976, que llevaba por título: "Los ex campeones, una prueba en contra del boxeo profesional", en el que denunciaba que algunos ídolos de los sesenta y setenta vivían en la miseria a pesar de las ingentes sumas cobradas en sus combates.

4 Con ocasión de un combate de Urtain en el que se proclamó campeón de Europa de los pesos pesados, El Correo Catalán escribía: "el boxeo sigue siendo un espectáculo bárbaro y denigrante, indigno de un país que se llama civilizado", citado en $A B C$ (24-VI-1970: 78).

5 En este país existía la variedad que ellos llamaban savate y los extranjeros "boxeo francés", en la que, junto a los puños, también se utilizaban los pies. Para mayor información sobre la historia de este deporte en Occidente, pueden verse Cebrián Boné (1989) y Cardells Martí y Gener Galbís (2004). 
ver en las noticias que aparecen en dos periódicos de aquellos años como el madrileño $A B C$, nacido en 1903, y el barcelonés El Mundo Deportivo, cuya aparición data de $1906^{6}$.

\section{LA LENGUA DEL BOXEO}

Y, sin embargo, a pesar de la mala reputación que hoy tiene y la escasa atención que se le presta, el boxeo es uno de los deportes que más presente está en el inconsciente lingüístico del castellano. Junto con el fútbol, ha sido el que más ha contribuido a enriquecer y vigorizar el acervo común de la lengua, aportando términos y locuciones muy características en la expresión estándar.

La lengua del boxeo nace y se desarrolla en España a medida que los periódicos y revistas se van ocupando de él, primero someramente, con escuetas noticias en los primeros años del siglo y poco a poco con el despliegue de crónicas más detalladas y laboriosas en paralelo a su creciente interés. En este sentido, es muy ilustrativo seguir la evolución de la historia y el tratamiento de este deporte en dos periódicos que nacieron en España, como él, con el siglo XX, cual es el caso de los ya mentados $A B C$ y El Mundo Deportivo. En la tercera década del siglo hay que añadir a Excelsior, un periódico bilbaíno especializado en deportes que aparece en 1923. Precisamente, tras la introducción y primeros escarceos de la práctica boxística en los dos decenios iniciales del siglo, los años veinte pueden considerarse como los de la gran eclosión de este deporte, pues España logra con Antonio Ruiz el primer título europeo y surge el fenómeno de Paulino Uzcudun, que aspira a hacer carrera en la máxima categoría y para ello compite en Estados Unidos, la meca entonces del mundo profesional del pugilismo. En estos años los combates más importantes tanto a nivel mundial como nacional son bien atendidos en la prensa, con un despliegue a veces extraordinario. Consecuencia de ello es que la lengua del boxeo conoce en esta década en nuestro país su mayor grado de ebullición y expansión, pues préstamos del inglés -que es la lengua putativa del boxeo, no sin cierta influencia del lenguaje francés de la esgrima-y adaptaciones, así como calcos y soluciones propias, van tomando forma y asentándose en la comunicación periodística para constituir la jerga propia que tanto le caracterizará. Así pues, puede decirse que antes de la guerra civil el lenguaje del boxeo ya estaba plenamente desarrollado, mientras que en el franquismo tuvo lugar su decantación y consolidación, así como su introducción en la lengua general. Esto último fue debido, sin duda, a la gran difusión que conoció entre el pueblo, por razones de interés comercial y político. Los años sesenta y setenta fueron la "época de oro" del boxeo español, omnipresente en la prensa general y deportiva y mimado por la televisión, que entonces no hurtaba información ni transmisiones en directo de los combates de las grandes estrellas nacionales. Sin duda, el oído se fue haciendo a su terminología esotérica y algunos de sus términos pasarían a estar en boca de todos y a servir a los grandes cronistas deportivos y políticos para dar realce y expresividad a su estilo con creaciones figuradas basadas en su jerga.

\footnotetext{
6 Alguna consideración literaria ha tenido el boxeo en España, aunque no tanto como en Norteamérica, donde siempre gozó de pujanza. London, Conan Doyle, Hemingway, Scullberg... se inspiraron en él para algunos de sus más apreciados relatos, mientras que Mailer y Talese le dedicaron reportajes inolvidables dentro de lo que se llamó el Nuevo Periodismo. En España se acuerdan de él en algunos de sus libros Ramón Gómez de la Serna y Jacinto Miquelarena, e inspira cuentos entrañables a Ignacio Aldecoa y al argentino Cortázar. Ha tenido también cronistas muy destacados que se han ocupado de su ejercicio en los periódicos con solvencia y brillantez, como Fernando Vadillo y Manuel Alcántara, Julio César Iglesias y Alfredo Relaño, y ahora mismo Emilio Marquiegui, Jorge Lera y David Gistau.
} 
Como la de cualquier otro deporte, la lengua del boxeo es una lengua sectorial que tiene su terminología específica. A diferencia del concepto de nivel o estrato lingüístico, que utiliza criterios sociológicos verticales para clasificar a los hablantes de una lengua, el concepto de lengua o lenguaje sectorial obedece a criterios sociológicos horizontales, pues sirve para incluir a las distintas jergas profesionales y demás lenguas afines que identifican a determinados grupos, profesiones y actividades sociales (Rodríguez Díez, 1981). Esta lengua se compone a partes parecidas de precisión técnica y creación periodística, e incluso popular, la del propio mundo del boxeo ${ }^{7}$. Entrenadores y periodistas introducen un léxico extranjero que, con el tiempo, se va asimilando tal cual, en su expresión foránea, o va buscando la mejor adaptación a la grafía, la fonética y la morfología del castellano. Y, al mismo tiempo, van creando en torno a él expresiones basadas en la capacidad de sustitución y creatividad semántica de la lengua para dar realce y emotividad en las crónicas -los periodistas-, así como un lenguaje más familiar en gimnasios y veladas -el mundo que vive de este deporte: promotores, preparadores, utilleros, púgiles...-. De cómo nace, penetra, se adapta, se crea y se expande este lenguaje en el castellano, en sus distintos niveles y con distintos procedimientos, trata este artículo. Para ello se hace un repaso a los modos de formación neológica más comunes de que hace gala, tanto a sus componentes léxicos, en la que entrarían los préstamos y adaptaciones, los calcos y las creaciones propias, como a los morfológicos, con formas de derivación y composición, así como a los morfo-sintácticos: locuciones y elipsis, y a los de inspiración semántica: metáforas y metonimias. Es decir, a los dos tipos reconocidos de formación neológica: la denominativa, impelida por la necesidad de designar lo nuevo, y la estilística, cargada de intención expresiva, propia de las crónicas periodísticas o del ingenio popular (Bordonaba, 2009).

La exposición que se hace es principalmente descriptiva, ya que intenta mostrar cómo, a la hora de dotarse de un corpus léxico, un lenguaje sectorial que bebe principalmente en fuentes extranjeras utiliza todos los recursos neológicos de que dispone la propia lengua. Como cualquier otro deporte, el boxeo ha sabido crearse la suya ${ }^{8}$.

Lengua que, dada la relevancia que el deporte ha obtenido en las sociedades modernas a medida que avanzaba el pasado siglo, ha ido penetrando en la lengua de la calle. Más allá de su propio reducto de profesionales y aficionados, los medios de comunicación lo han hecho posible. Por ello, también se considera la aportación de este léxico sectorial al conjunto de la lengua castellana en general, con su incorporación a la lengua diaria y la interactuación en otros lenguajes sectoriales, deportivos o no, mediante el uso figurado de sus expresiones o términos más peculiares. Tras poco más de un siglo de existencia, la lengua del boxeo tiene hoy su lugar propio en diccionarios, páginas periodísticas, conversaciones ordinarias y hasta en la literatura9.

7 Como expone Guerrero Ramos (1999) formaría parte de las lenguas especiales, aunque no del subgrupo de estas considerado como el de las especializadas o técnico-científicas. Sobre este tema remito a los estudios conocidos de Rodríguez Díez (1981), Cabré (1993), Lerat (1997) y Rodríguez-Piñero Alcalá y García Antuña (2009).

8 Remitimos a estudios sobre el lenguaje deportivo en general como los de García Turza et al. (1994), Hernández Alonso (2003) y Guerrero Salazar y Cremades García (2012), y a otros efectuados sobre deportes particulares como los de Castañón Rodríguez (1993), Herráez Pindado (2002) y Teruel Sáez (2006).

9 Remitimos a la bibliografía para constatar el corpus documental de donde se toman los datos para realizar este estudio. Es, preferentemente, prensa escrita que abarca desde los inicios de este deporte en España, en los primeros albores del siglo XX, hasta 2017. Se añaden también algunos tratados de este deporte, diccionarios deportivos y alguna recopilación de crónicas de un comentarista clásico como lo fue Alcántara (2014). De todo ello se da cuenta en la bibliografía final. 


\section{PRÉSTAMOS LÉXICOS}

Con los deportes, que en España entraron de fuera, pues en su mayor parte tienen origen inglés y francés, penetraron en nuestro idioma un buen número de palabras nuevas que eran necesarias para dar nombre a conceptos desconocidos. El lenguaje del ocio conoció a principios del siglo XX una inusitada entrada de neologismos que, en buena parte, quedaron en el idioma y se integraron perfectamente en su léxico (Alzugaray 1982; Loza y Castañón 2010). El boxeo no iba a ser menos, y trajo consigo en las primeras décadas del siglo pasado numerosos préstamos ingleses y franceses. Con el tiempo, irían decantándose, es decir, manteniéndose, adaptándose o desapareciendo.

El préstamo es un tipo especial de neologismo y, en cuanto procede de un sistema lingüístico distinto, se ha considerado como un recurso neológico externo, que se diferencia de otros propios recursos internos que posee la lengua para ampliar su caudal léxico. Generalmente suele distinguirse entre los procedimientos formales (neología formal) y los semánticos (neología semántica), aunque hay fenómenos que nunca acaban de delimitar bien sus fronteras (Gómez, 2005).

De todas formas, algunos préstamos se toman tal cual, manteniéndose intactos en la nueva lengua. Serían los préstamos puros, también conocidos como peregrinismos o xenismos (Gómez, 2005: 27-29). Voces provenientes del inglés que todavía prevalecen tal como entraron en las crónicas de hoy serían ring, ringside, round, punch, lucky punch, punch ball, sparring, clinch, knock out, knock down, K.O., groggy, no contest, manager, jab, uppercut, swing, hook, cross, out, break, welter, speaker y gong. Casi ya no se escriben otras como punch drunk y match-maker. Sí que es verdad que algunas de estas alternan con adaptaciones a la fonética y la grafía castellanas, como sucedió con boxeo (boxing) y sus derivados boxear (box) y boxeador (boxer) ya en el siglo XIX. Antes de la guerra civil ya se utilizaban gongo, nocaut y noquear, y hoy van ganando terreno grogui, espárrin o wélter, aconsejados por la RAE (2005 y 2010) o Fundéu. Al mismo tiempo, algunas de ellas alternan con otras opciones autóctonas. Así, tenemos alternancias como ring / cuadrilatero; ringside / primera fila; round / asalto; punch / pegada; speaker / locutor; knock out / fuera de combate; no contest / pasividad; punch drunk / sonado; match-maker / promotor..., y en los golpes se dan parejas como swing / bolea y cross / cruzado.

Hay que añadir los seudoanglicismos acuñados en Francia y traspasados al español (Rodríguez González 2013): challenger, punching ball, puncheur, forcing y footing. El primero alterna con aspirante o candidato; el segundo, con balón o pera. Y los galicismos introducidos por el inglés: match, avant match y crochet. El primero alterna con combate o encuentro; el tercero también se adapta en croché o se sustituye por gancho.

Es común entre deportes prestarse términos o compartirlos. La esgrima desarrolló en el siglo XVIII sus reglas y su lenguaje en Francia y las traspasó a Inglaterra, tomándose en este país para el boxeo no pocos términos como asalto (assaut, fr. / assault, ing.), ataque (attaque, fr. / attack, ing.), ofensiva (offensive, fr. / offensive, ing.), contra (contre, fr. / counter, ing.), directo (direct, fr. / direct, ing.), defensa (défense, fr. / defense, ing.), desplazamiento (déplacement, fr. / displacement, ing.), distancia (distance, fr. / distance, ing.), esquiva (esquive, fr. / esquive, ing.), finta (finte, fr. / feint, ing. ), guardia (garde, fr. / guard, ing.), parada (parade, fr. / parade, ing.), respuesta (riposte, fr. / riposte, ing.), coquilla (coquille, fr. / coquille, ing.) y algunos más. En castellano se adaptaron o se tradujeron sin más. 


\section{PROCEDIMIENTOS MORFOLÓGICOS}

Empezaremos por los procedimientos típicamente formales de adaptación de préstamos al sistema lingüístico español. Morfológicamente, la lengua del boxeo registra también ciertas características, en su mayor parte debido a la forma de traducir o adaptar el léxico que venía de las crónicas inglesas y francesas. Por ejemplo, en la formación de plurales de préstamos tomados en bruto, añadía -s: manager-s, welter-s, sparring-s, o - es: clinch-es, punch-es: "Acortó distancias y con un fulminante ataque de "punches" como dicen los ingleses, dejó cerrado el ojo izquierdo del galés" ( $A B C$ 25-VII-1968: 71) ${ }^{10}$.

Los mecanismos formales más socorridos a la hora de adaptar neologismos son la derivación (prefijación, derivación, parasíntesis) y la composición. Hagamos un repaso de estos:

\subsection{La derivación}

La derivación es un procedimiento de gran fecundidad y eficacia para dotar a la lengua de nuevas palabras a base de añadir a un lexema o raíz una serie de afijos, que bien pueden ser prefijos o sufijos. Mientras con la prefijación la categoría gramatical de la nueva palabra no cambia respecto a la de la palabra que sirve de raíz, con la sufijación es muy habitual que el resultado sea una nueva palabra de categoría gramatical distinta a la de la primitiva. La lengua del boxeo no es pródiga en el procedimiento de la prefijación, y, además, este lo trataremos como una de las variantes de la composición. Sí que es pródiga en formación de nuevas palabras por sufijación, repartidas en las tres principales categorías de sustantivos, adjetivos y verbos.

Empezaremos por la sufijación simple o inmediata. Es la formada por una serie de palabras átonas terminadas en $-a$ que son producto de la adaptación o traducción de palabras inglesas o francesas y que denotan acciones: defensa (defense / défense), guardia (guard / garde), esquiva (esquive / esquive), finta (feint / finte) falta (foult / faute) y contra (counter / contre). Todas ellas provienen de la esgrima, lo mismo que coquilla (coquille / coquille), que designa el aparato protector del bajo vientre. Algunas de ellas como defensa, guardia, o distancia (distance / distance) tenían ya existencia en castellano, aunque ahora añaden un nuevo valor semántico. Otras son por entero novedosas, como esquiva, que, aunque sí existía el verbo "esquivar", no existía como sustantivo o `acción de esquivar': "el inglés demostró sus habilidades y recursos defensivos en una esquiva en cuerdas y en el rincón" ( $A B C$ 4-III-1978: 42). Sería una derivación "regresiva posverbal", nacida de trasponer la $3^{\text {a }}$ persona del presente de indicativo del verbo (Casado, 2015: 43). O contra, sustantivo formado de la simplificación de la lexía compuesta francesa contrecroissé: "El italiano consigue una contra al tórax de Legrá que le hace retroceder" $(A B C$ 15-VIII-1971: 39).

Adentrándose en las sufijaciones mediatas o propias de carácter nominal, hay que considerar los sustantivos de acción con sufijo - eo, derivados de verbos extranjeros, como boxeo (box) o bloqueo (block), que conllevan verbos en -ear: boxear, bloquear. Otras palabras

10 Las citas que sirven de ejemplo a los términos o expresiones aludidas se toman casi exclusivamente del $A B C$ de las décadas sesenta y setenta del siglo pasado, que se corresponden, como ya está dicho, con la época de apogeo de este deporte en la sociedad española y con la eclosión de su léxico en los medios de comunicación social orales y escritos. 
con este sufijo, como punteo o tanteo, tienen carácter propio y originan verbos derivados como puntear y tantear: "El primer asalto fue apenas de tanteo; los púgiles brincaban sobre la lona" ( $A B C$ 7-IX-2006: 59).

Mención aparte merecen los aumentativos en - azo, tan habituales para designar un golpe (Monge, 1972). Derivados de un sustantivo, indican la acción o la forma de asestar el golpe, caso de guantazo, derechazo, izquierdazo, zurdazo: "Más de siete minutos necesitó Mike Barry para recuperarse del derechazo, seguido de un potente izquierdazo, que le conectó Bob Foster en el cuarto asalto" ( $A B C$ 29-VI-1972: 43). Otras veces toman cariz metafórico y señalan igualmente la especial contundencia e intensidad del golpe, como sucede cuando se habla de martillazo, mazazo, latigazo... Caso aparte sería el sufijo alomorfo -etazo en puñetazo, que aunque se asocia a 'puño', se origina más bien en 'puñete' (RAE 2009: 298). Este tipo de derivación tiene carácter aumentativo de ponderación o apreciación y se está revelando muy creativo en el español actual, sin duda el que más entre los prefijos aumentativos, debido al amplio abanico de valores y funciones que lo caracterizan (Falcinelli, 2007). Tan elevada productividad es propia del lenguaje deportivo, proclive a recargar el componente expresivo.

Sustantivos deverbales que denotan acción y efecto son los terminados en -aje: pesaje, vendaje, blocaje, arbitraje..., que se forman desde muy antiguo por asimilación del francés -age. "La escena del pesaje de los púgiles fue otro golpe publicitario" (ByN 29-II-1964: 8). Y otro sufijo muy productivo es -ada, que según Lang (1992: 94-95) tiene un marcado carácter coloquial y cierto sentido apreciativo, lo cual se cumple en el neologismo propio pegada, que contrarresta el inglés punch: "Alí tiene treinta y cinco años, y se le notan. Desde los "michelines" a la falta de pegada y resistencia" (ABC 18-V-1977: 67). También parada, cuando con un brazo se evita el golpe del contrario, tomado del francés parade. A principios de siglo se usó esquivada, como alternativa de esquiva, pero terminó imponiéndose esta.

Sustantivos deverbales son también los terminados en - dor, para clasificar a una persona por su profesión, y tal es el caso de boxeador, pero también sirven para hacer referencia a ciertas cualidades o acciones propias de esas personas, por lo que adoptan un perfil caracterizador (Santiago Lacuesta 1999: 4543-4544). A los púgiles se les califica, según sus condiciones, de pegador o golpeador (puncher ing.; puncheur, fr.) si tienen una fuerte pegada; de fajador (y peleador o luchador) (slugger, brawler, ing. battant y bagarreur, fr.) si buscan de continuo el ataque y la acción: "Contra Pedro Carrasco fue boxeador y "fajador" al tiempo, frente a un boxeador-pegador" (ABC 31-I-1970: 59). Encajador (y asimilador) (durable, ing.; encaisseur, fr.), si saben sufrir y asumen con aguante los golpes del contrario. Contragolpeador (counter-puncher, ing.) si saben provocar y esperar el ataque del otro para colocar sus golpes. Estos nombres caracterizadores funcionan también como adjetivos, e incluso el clasificador, en intensificaciones como esta: "Legrá, al margen de los resultados que haya obtenido por la vía rápida, es un "boxeador-boxeador" de elegante línea" ( $A B C$ 25-VII-1968), que el cronista utiliza para expresar que tal púgil sabe atacar y defenderse, que da espectáculo porque es completo.

La caracterización de los púgiles echa también mano de adjetivos que derivan de nombres con sufijación -ista, como esgrimista, cuando esquivan bien los golpes, y estilista, los que saben moverse, cuidan su pegada y aprovechan los fallos del otro; los que, en una palabra, dirigen el combate o "saben leer" en él: "El argentino Miranda es un fino estilista, de guardia abierta, pega con las dos manos y tiene boxeo atractivo" (ABC 11-III-1967: 105). A 
estos también se les denomina "técnicos" e incluso "científicos". Ambos términos son adaptaciones de los anglicismos esgrimist y stylist. También existe pugilista en doble categoría, como adjetivo: “(...) Rey Rovira, vieja gloria pugilista del Borne (ABC 24-VIII-2003: 22), y como sustantivo: "ganó cinco títulos en cinco pesos distintos y se labró una leyenda de formidable pugilista" ( $A B C$ 17-XII-2007: 96).

La derivación adjetival más característica sería -ístico en dos palabras fundamentales como boxeo y púgil: boxístico y pugilístico, adaptaciones de los adjetivos ingleses boxistic y pugilistic, que aparecen ya en las primeras décadas del siglo pasado: "Después de un historial pugilístico inmejorable, después de subir la parte penosa de la cuesta de su vida pugilística..." (ByN 7-III-1926: 74).

En cuanto a los verbos, destaca la tendencia a elegir el sufijo derivativo - ear en derivaciones de anglicismos, como es el caso de boxear, bloquear, noquear, jabear, clinchear..., que se unen a los nativos golpear, pelear, tantear, puntear, martillear... El sentido de este derivativo es expresar la iteración o la frecuencia, y según Casado (2015: 41) deja entrever connotaciones apreciativas. Esta sufijación verbal basada en nombres extranjeros es, por otra parte, muy habitual en la lengua deportiva. Y son dignos de mención dos verbos formados de vocablos ingleses como conectar (connect) e impactar (impact). Lo mismo que otra serie que tienen que ver con acciones de esgrima que adopta el boxeo, y por tanto de origen francés con asunción inglesa, tales como cruzar (croiser, fr.; cross, ing.), batir (battre, fr.; beat, ing) o tocar (toucher, fr.; touch, ing.): "En el noveno continuó Folledo su ofensiva y volvió a tocar al negro" ( $A B C$ 10-IX-1966: 59). Son verbos que toman nuevas acepciones en castellano, al igual que otros como entrar: "Velázquez, jugándoselo el todo por el todo, entró en la guardia del italiano para dominarle" (ABC 30-VI-1971: 64) y doblar: "Holmes siguió con su labor de golpear con la izquierda y doblar con la derecha" (ABC 12-XI-1978: 39). También los hay que se forman por adaptación de otros foráneos, como contrar (contrer, fr): "Nando contra mal y Folledo esquiva ( $A B C$ 10-IX-1966: 59) o por derivación del sustantivo adoptado, como fintar, también herencia de la esgrima: "Velázquez se mueve con algo de rapidez y empezando a fintar bien, buscando la entrada en la guardia de Puddu" (ABC And. 30-I-1971, 49).

Se dan también una serie de verbos formados mediante la parasíntesis, como acometer, acorralar, arrinconar, encajar (encaisser, fr). y los pronominales: agazaparse, enrocarse... Pronominales no parasintéticos serían caerse, derrumbarse, tambalearse, desmoronarse, sobreponerse..., además de los reflexivos como: fajarse, abrirse, cerrarse, defenderse, guardarse, cubrirse (couver-up, ing; se couvrir, fr.): "Evangelista, algo apagado y encogido, consideró que debía cubrirse y esperar ese ataque de Dante...” (ABC 27-XII-1978: 37) y los recíprocos: enfrentarse, tantearse, castigarse, agarrarse, separarse, trabarse: “(...) para trabarse ambos púgiles y terminar el asalto" ( $A B C$ 22-I-1969: 62).

\subsection{La composición}

La composición es la unión de dos o más palabras que, como lexía compleja y no en su habitual uso independiente, aportan un significado único, nuevo en la lengua. Es un fenómeno neológico no excesivamente frecuente en español, pero que tiene su importancia en la jerga boxística, sobre todo en los llamados compuestos sintagmáticos. Ello será debido a los frecuentes calcos que hace de las fuentes originarias -inglesas y francesas- a las que acude 
para elaborar su léxico. La consideración de los procesos compositivos compete tanto a la grafía como a la morfología, al léxico, la sintaxis y la semántica, e incluso a la terminología (Tenorio, 2005). Primaremos el enfoque sintáctico que lleva a cabo Alvar Ezquerra (2012) con su clasificación y nomenclatura.

Las creaciones univerbales o compuestos por yuxtaposición, que forman una unidad léxica por amalgama gráfica y fonética de los dos términos, son contadas en la lengua del boxeo, pues apenas se puede aludir a salvaencias, el golpe denominado sacacorchos, calco del inglés (corkscrew), y cuadrilátero, pero el maridaje de dos palabras o sintagmas que, aunque siguen conservando su independencia gráfica, forman una unidad semántica es mucho más abundante.

Entre las unidades biverbales, también llamados compuestos sintagmáticos por Almela (1999: 145), solo algunas aparecen ligadas por un guión. Siempre refiriéndose a la forma y disposición de los golpes, como es el caso de uno-dos (one-two, ing.; une-deux, fr.): "Clay alcanzó a Querry al salir de las cuerdas con otra potente combinación de uno-dos" ( $A B C$ 29VI-1972: 44), cuyo equivalente es un derecha-izquierda o un izquierda-derecha, y también el llamado bolo-punch, utilizado por contados púgiles, como el legendario Pedro Carrasco, del que se dice en cierta ocasión: "llegó a hacer una magnífica demostración de lo que es el "bolo-punch", golpe que posee más espectacularidad que eficacia" (ABC And. 30-IV-1967: 109). La estructura es de $\mathrm{S}+\mathrm{S}$, y habría que añadir juez-árbitro (o juez árbitro). Se forman por contraposición; es decir, los dos términos están al mismo nivel, no hay un núcleo o base y un determinante o predicado, como sí sucede en las que se forman por disyunción, en que el primer término es la base y se ve determinado por el segundo, que suele ser un adjetivo u otro sustantivo.

Entre este tipo de compuestos sintagmáticos, característicos son los de estructura $\mathrm{S}+$ $\mathrm{S}$, fruto del calco o adaptación de denominaciones foráneas: peso mosca (flyweight, ing.), peso gallo (poid cocq, fr.), peso pluma (featherweight, ing.), peso wélter (welterweight, ing.), y peso crucero (cruiserweight, ing.) Pero más los de estructura $\mathrm{S}+\mathrm{Adj}$, como sucede para denominar otros pesos o categorías: peso ligero (lightweight, ing.), peso medio (middleweight, ing.), peso pesado (poid lourd, fr.)... A ellos habría que añadir los que aportan el adjetivo prefijado: peso superligero, peso semipesado, peso superpesado...; y también se distinguen, más genéricamente, los pesos altos o grandes pesos y los pesos bajos: "nunca hay que subestimar a los guerreros asiáticos, principalmente de pesos bajos" (M 20-III-2017: 44). Para distinguir el modo de la guardia: guardia francesa, guardia americana, guardia centroeuropea, cuyas particulares características las explica el exboxeador medalla olímpica Rodríguez Feu (1987: 74), o guardia abierta (open guard, ing.) y guardia cerrada (closed guard, ing.), guardia alta (high guard, ing.; garde haute, fr.) y guardia baja (low guard, ing.; garde basse, fr.): "El italiano presenta una guardia cerrada, mientras que Legrá hace su clásica guardia baja" (ABC 15-VIII-1971: 39), y todavía hay guardia frontal (front guard, ing.; garde frontale, fr.) e incluso guardia cambiada (changed guard, ing.): "Pega con las dos manos, aunque no es un zurdo, aunque pelee con la guardia cambiada" ( $A B C$ 7-XII-1963: 77). También a la hora de distinguir los golpes se dan diversas conjunciones fosilizadas, pues se habla de golpes cortos, golpes largos: "Después de una esgrima de tanteo, el español lanzó varios golpes largos que tocaron el rostro del campeón" ( $A B C$ 25-VII-1968: 71); golpe lateral, golpe directo y, sobre todo, golpe bajo (low blow, ing.; coup bass, fr.) de especial significación: "Urtain ha conocido 
la primera derrota de su vida pugilística, al ser descalificado por golpe bajo" ( $A B C$ And. 2-VIII-1970: 67). La distancia sirve para dirimir la forma que adoptan los púgiles de pelear, según sus condiciones o características, y así, aunque en este caso el adjetivo suela anteceder al sustantivo, se habla de larga distancia (long-range, ingl.; longue distance, fr.), corta distancia (close-range y short distance, ing; courte distance, fr.) y media distancia (middle distance, ing.; mi distance, fr.): "En el tercer asalto, Legrá se dedicó a exponer, abriendo su guardia y tratando de provocar al australiano al combate a la media distancia" ( $A B C$ 22-I-1969: 62). Como vemos, este tipo de composición es muy fecundo para formar conjuntos escalares en una gradación real (el peso o categoría de los púgiles, las formas de defenderse, los tipos de golpes, el grado de aproximación al contrario) y viene como préstamo adaptado de las lenguas de donde se toma.

Otros característicos sintagmas trabados de $\mathrm{S}+\mathrm{Adj}$, ya formularios, son combate nulo, título absoluto, para referirse al título mundial de una categoría, juez único, cuando el árbitro no tiene los dos jueces habituales que lo asistan, k.o. técnico: "En el quinto asalto, míster Harry Gibbs, árbitro y juez único de la contienda, interrumpió el combate. Era un k.o. técnico con todas las de la ley" (ABC 25-VII-1968: 71). Como ejemplo de estructura Adj. + S: doble contra.

Hay que advertir que algunos de estos compuestos presentan una disposición híbrida, es decir, conjuntan una palabra tomada de otra lengua con una propia, como sucede en match nulo (null match, ing.; match nul, fr.), peso wélter, bolo-punch, $k$. o. técnico...

Numerosos y variados son también los sintagmas compuestos con estructura preposicional (S prep S), que Alvar recoge bajo la denominación de sinapsias (2012: 24-27) También aquí hay sustantivos nucleares que dan lugar a composiciones variadas: golpe (de izquierda - de derecha - de revés (backhand, ing.) - de bolea - a la contra (counterpunch, ing.), en todas ellas el segundo término determina, concretando su modo; en cambio, en golpe de gracia o golpe de suerte la trabazón semántica de ambas lexías es mucho mayor, al indicar no el modo del golpe, sino su resultado. El segundo compuesto es fruto del calco del inglés lucky punch. Determinación múltiple tiene también victoria (a los puntos o por puntos - por K.O. - por inferioridad o por k.o. técnico (technical knockout, ing.) - por abandono - por descalificación...) y categoría (de los plumas - de los wélter - de los medios...) Otras lexías interdependientes y muy utilizadas son guantes de boxeo (boxing gloves, ing.; boxe gants, fr.), juego de piernas (o de pies) (footwork, ing.; jeu de jambes, fr.; juego de las cuerdas; combinación (o serie/s) de golpes (combination o series of punches, ing.); intercambio de golpes (exchange of blows); combate (o pelea) de revancha, asalto de tanteo, asalto en tablas, boxeo en línea: "Billy Aird ha intentado ser campeón con unos atisbos de boxeo en línea" ( $A B C$ 4-III-1978: 42). Los puede haber con un adverbio en segundo lugar: paso atrás, golpes por dentro: "Benvenuti es rápido, contundente y fue perfecta su aplicación de mano derecha en un golpe "por dentro" ( $A B C$ 16-X-1965: 93).

Tanto en estos compuestos preposicionales como en los sintagmáticos por disyunción de estructura $\mathrm{S}+\mathrm{S}$ se admite el plural, que morfológicamente solo se marca en el primer término: juegos de piernas, pesos mosca..., y en los de estructura $\mathrm{S}+\mathrm{Adj}$. en ambos términos: pesos pesados, golpes bajos...

Un quinto grupo de compuestos serían los que, en su formación, admiten prefijos cultos. Estos, según Alvar (2012: 25-27), son de difícil encasillamiento, pues su función diverge del resto de afijos. Se toman, una vez más, tal como vienen del inglés o el francés, caso 
de contre- en palabras como contraofensiva (counter-offensive, ing. / contre-offensive, fr.), contraataque (counter-attack, ing. / contre-attaque, fr.), contragolpe (counterpunch, ing.). $\mathrm{O}$, si se convierten en verbos, contraatacar, contragolpear, contrarrestar: "Folledo contrarresta y golpea a su contrario, el cual cae junto a las cuerdas" ( $A B C$ 6-XII-1968: 87). Semi- y super- entran en juego para nombrar ciertos tipos de pesos o categorías que están inmediatamente por debajo o por encima del rango que modulan: semimosca (y minimosca), semipesado (lightheavyweight, ing.), superligero (superlightweight, ing.), superwélter, superpesado. En este último caso estaríamos antes triples lexías: peso superligero o peso semipesado. Si contra- añade un sentido de orientación o disposición, semi- y super- adquieren carácter apreciativo en una serie gradual o escalonada.

No es lo más habitual, pero en ocasiones la composición adquiere un carácter más complicado y diverso al reunir más de dos lexías. Es curioso el caso de cinturón arcoiris, compuesto sintagmático de tres términos: un compuesto por disyunción doble. Y luego están otros casos más complejos que forman lo que se ha venido a llamar unidades léxicas pluriverbales (Lang, 1992) o unidades terminológicas plurilexemáticas (Cabré, 1993): serie de ambos puños, victoria por la vía rápida, puesta en juego del título...

\section{PROCEDIMIENTOS SINTÁCTICO-SEMÁNTICOS}

En ocasiones, una palabra pierde su independencia léxica para agruparse en expresiones complejas en las que ha de adaptarse a un significado nuevo y conjunto, como sucede en las locuciones. O transforma el significado primitivo al tomar las referencias del término al que matizaba, como sucede en las elipsis; en este procedimiento, el término superviviente sufre una conversión de categoría gramatical o metábasis. Es decir, ambas combinan, junto a las nuevas valencias semánticas, una intensión sintáctica nueva.

\subsection{Unidades fraseológicas y otras solidaridades léxicas}

Desde que Casares (1950: 170) escribiese sobre el concepto de locución como "combinación estable de dos o más términos que funciona como elemento oracional y cuyo sentido unitario consabido no se justifica, sin más, como una suma del significado de sus componentes", la lexicología ha continuado dirimiendo el verdadero sentido, forma y función de las lexías complejas fijamente recreadas, aunque ha optado por una denominación más genérica como es la de fraseología o unidades fraseológicas. La delimitación del concepto varía de unos estudiosos a otros, pues si Corpas (1996) lo hace extensivo tanto a fórmulas fijas o lexicalizadas como semifijas, otros prefieren hacer distingos según el grado de fijación y de idiomaticidad o unificación semántica de sus elementos, separando perfectamente unidades fraseológicas y colocaciones (Bosque, 2001; García-Page, 2008). Las locuciones, por su parte, no siempre son fáciles de distinguir de los llamados compuestos sintagmáticos, aunque la NGLE (RAE y AALE, 2009: 58-62) lo dirime diciendo que las primeras presentan el máximo grado de opacidad semántica y las segundas dejan entrever cierta trasparencia en su composición.

Hay quienes prefieren resaltar en las locuciones un grado de expresividad que no tienen otros compuestos sintagmáticos, lo cual se demuestra cuando aquellos son reemplazados por sus equivalentes verbales (que no siempre los tienen) (Osorio y Serra, 2012: 112-113). 
Sería el caso de las locuciones más aparentes del boxeo, algunas de ellas de gran éxito en el lenguaje coloquial. Expresividad que, por otra parte, exige la emotividad del combate y que los periodistas saben alimentar. Con un sentido amplio, las clasificamos según su valor funcional en la oración:

Valor verbal (estructura $\mathrm{V}+\mathrm{CD}$ ): cruzar los guantes: enfrentarse dos púgiles o caombatir; colgar los guantes (to hang up the gloves, ing.): retirarse, abandonar el boxeo; calzarse los guantes: boxear o entrenar; hacer guantes: modo de entrenamiento; armar la guardia (to arm the guard, ing.; armer la garde, fr.) y bajar la guardia: ponerse en guardia y descuidarla respectivamente; besar la lona (el tapiz), morder el polvo (to make someone bite the dust, ingl.) y escuchar la cuenta: ser derribado o caer a consecuencia de un golpe; meter el puño y soltar el puño (el brazo): lanzar un golpe al rival; mantener la distancia: propio de quien boxea a la contra; buscar el cuerpo a cuerpo: pelear en corto, propio de quien tiene menor estatura y brazos más cortos que su rival; castigar el hígado: lanzar sus golpes a esa zona del rival; tirar (arrojar, lanzar) la toalla (to throw in the towel, ing): retirarse de la pelea: "Venció Martínez por abandono de Pinto en el noveno asalto, al arrojar la toalla los cuidadores del aspirante" ( $A B C$ 14-IX-1968: 67). Y aún Rodríguez Feu (1987: 60 ss.) describe ciertas técnicas que se utilizan tomando a las cuerdas como cómplices y que llevan por nombre: hacer el arco, medir el ángulo, trenzar la cuerda... Es verdad que no todas ellas muestran el mismo grado de opacidad, pero sí son expresiones lexicalizadas o institucionalizadas en la lengua boxística.

Valor adjetivo tienen otras como estar grogui (to be groggy, ing.) y estar sonado (être sonné, fr.), que significan lo mismo: estar aturdido, semiconsciente. Estar tocado (to be touched, ing.), en cambio, se dice cuando al púgil se le ve disminuido de facultades por los efectos de uno o varios golpes precisos, pues la expresión inglesa touch shot se traduciría por "golpe de precisión". O ser salvado por la campana (saved by the bell, ing.): el término del asalto alivia al púgil en apuros...

Valor adverbial $(\mathrm{V}+\mathrm{CC}$ ) adquieren más bien ponerse en guardia (to place on guard, ing.); boxear a la contra, boxear en corto, mantener a distancia (maintinir à distance, fr.), entrar en clinch, entrar en el cuerpo a cuerpo (corps à corps, fr.).

Valor prepositivo habría en dejar fuera de combate (hors combat, fr.).

Como colocaciones habría que calificar a otras combinaciones frecuentes de palabras que no muestran tan nítidamente el grado de fijeza ni el de cosemanticidad de sus elementos. Estarían a medio camino de las combinaciones fijas y las totalmente libres. Sería el caso de expresiones complejas como enviar a las cuerdas (renvoyer dans les cordes, fr.); refugiarse en las cuerdas, salir de las cuerdas, acostarse en las cuerdas... o aquellas que permutan algunos de sus miembros (preferentemente el verbo): subir (saltar) al ring (jump into the ring, ing.; monter sur le ring, fr.) lanzar (enviar) a la lona, poner (llevar) contra las cuerdas (to push up against the ropes, ing.); contar hasta ocho (hasta diez) (count to eight (to ten), ing.).

La NGLE (2009: 58-62) reconoce dichas colocaciones con la denominación de grupos sintácticos, los cuales se reiteran una y otra vez en las crónicas, siempre en torno a una palabra nuclear, como golpe/s, que atrae a su órbita una serie de verbos como: colocar: (place, ing.) "Legrá se lanzó al ataque para colocar varias series con ambas manos a la cabeza de Famechon" (ABC 27-I-1969: 62), asestar, propinar, conectar, rehuir, esquivar, desviar...; como guardia con abrir, cerrar, romper...: "Pese a esa ofensiva desatada por el 
californiano, nunca llegó Nando Ramos a romperle la guardia a Carrasco ni a ponerle en serio peligro" (ABC 29-VI-1972: 43). Este último verbo también casa con distancia (break the distance, ing.; casser la distance, fr.). Con titulo: conquistar, arrebatar, retener... Otras veces es el verbo el que reúne en torno a sí una serie de sintagmas preposicionales, como vencer (ganar) por K.O., por la vía rápida, por puntos o a los puntos, por inferioridad del rival, por K. O. técnico, por abandono del rival...

\subsection{La elipsis}

El concepto de elipsis como procedimiento semántico fue introducido por Ullman (1952: 238), y se ha revelado como un aliado de excepción a la hora de explicar la tendencia natural de toda lengua a la economía expresiva. En el corpus léxico del boxeo no podía ser menos, pues está presente en numerosas ocasiones. Siempre que se quiere calificar a un boxeador se echa mano sin más del calificativo y se le sustantiva: un estilista, un fajador, un encajador, un pegador: "Carrasco es un pegador nato" (ABC 11-V-1968: 101)... Otro tanto se hace al aludir a la categoría de los pesos: los pluma, los gallo, los welter, los medios: "Folledo retuvo su título nacional de los medios" ( $A B C$ 4-XII-1968: 67). Y lo mismo al aludir a los golpes que propinan o reciben, tanto el adjetivo como el sustantivo determinante se independizan: un corto, un directo, un gancho, una contra, un lateral, un cruzado, una derecha: "Cooper le alcanzó con un directo y un derechazo" ( $A B C$ 11-XI-1970: 85). Estos ejemplos son casos fehacientes de creación de hipónimos: de clases de boxeadores según su técnica, de categorías clasificatorias según el peso, de tipos de golpes (Carbonero, 1979).

La misma elisión del término rector se produce en las referencias al aspirante (boxeador que lucha por conquistar el título) o al segundo o preparador y acompañante en el ring, (second, ing.). Incluso la revancha fue en un principio el combate revancha o de revancha: "Combate revancha entre los fuertes púgiles Martínez y Barbens, a ocho rounds..." ( $A B C$ 22-XI-1922: 21). En otras ocasiones el término elidido es el secundario, el complementario del término principal, como sucede cuando se habla de la cuenta (de segundos) en los derribos o de serie/s (de golpes): "Legrá se lanzó al ataque para colocar varias series con ambas manos a la cabeza de Famechon" (ABC 22-I-1969: 62) o combinación/es: “...consiguió lanzar una combinación con Selby en las cuerdas” (M 5-III-2017).

Como muy bien ha estudiado Paredes Duarte (2009), la palabra que permanece adquiere el significado de todo el grupo léxico con que se combina, pues las desaparecidas proyectan sobre la superviviente su valor: los gallo (categoría de los pesos gallo); una derecha (un golpe dado con la derecha)... Igualmente apunta cómo, con frecuencia, tiene que ver con otros fenómenos semánticos como la polisemia, pues gancho, cuenta, saco... añaden nuevos significados a palabras que ya existían en castellano; o con la metáfora: pluma, gancho, sacacorchos, etc.

En cuanto a la siglación, solo se ha adoptado el K.O (o k.o., con minúsculas), procedente del knock-out inglés y el K.O.T (technical knock-out, ing.). También conoce los acortamientos, hechos por traducción, como cruzado (cross-counter punch, ing.), contra (contre croisé, fr.), balón (punching-ball), saco (punching bag, ing. y sac de frappe, fr.), y dos anglicismos puros como ring, acortamiento de boxing ring, y sparring, de sparring partner. 


\section{PROCEDIMIENTOS SEMÁNTICOS}

La lengua deportiva echa mano de numerosos sinónimos, unos siguiendo los mecanismos denotativos, y otros acudiendo a auténticas creaciones semánticas que se saltan la univocidad para recurrir al valor connotativo de las figuras literarias, tales como la metáfora y la metonimia. Es normal, dada la recurrencia de las situaciones que las crónicas tienen que referir y los valores emotivos que añaden a los sucesos en sí. Ello hace que el deportivo sea, en general, un lenguaje pintoresco, hiperbólico, "casi extravagante en algunos casos" (Oliva Marañón 2012: 18).

Sinonimia hay en voces intercambiables como ring - cuadrilátero - lona - tapiz...; punch - golpe - puñetazo - impacto - mandoble...; ataque - ofensiva - acometida - embestida ...; challenger - aspirante - candidato - retador...; o, para terminar, los numerosos vocablos que hablan del match primitivo inglés (o francés, de la esgrima) en el que dos púgiles miden sus fuerzas: combate - lucha - pugna - pelea - enfrentamiento - confrontación - duelo - choque - contienda - disputa - refriega - partida - encuentro... A las primitivas voces importadas del inglés o del francés, enseguida se les buscó sustitutos y equivalencias en el castellano.

También la polisemia ha conocido un importante desarrollo con este deporte, tal como se puede apreciar en las nuevas acepciones que el DRAE y otros diccionarios han incorporado a viejas palabras como velada, asalto, cuerdas, cuenta, baile, doblar, entrar, responder: "Ortiz ha dominado en varios asaltos, y White ha respondido siempre" ( $A B C$ 23-XII-1967: 77) y otras. La expresión levantar el brazo, puede significar dos cosas: que el árbitro proclame vencedor a uno de los contendientes: "el árbitro se da cuenta de la situación y, para evitar un castigo innecesario y peligrosísimo, corta el combate y levanta el brazo de Papp, en señal de vencedor por inferioridad" ( $A B C$ 7-XII-1963: 77), o que uno de los contendientes se dé por vencido: "a la mitad del cuarto asalto el veterano púgil italiano levantó el brazo en señal de abandono" (ABC 23-XII-1978: 37).

\subsection{La metáfora}

La metáfora es un recurso muy creativo que está en todo momento presente en la lengua, y aunque se asocia preferentemente a la poesía y a la escritura cuidadosa y literaria, se hace, sin embargo, omnipresente en el lenguaje diario, y no falta en las jergas más abstrusas. Muchas de las metáforas de la lengua ordinaria no parecen tales porque, de tanto usarlas, su originalidad parece eclipsada, el lector ya no la percibe. En boxeo sucede con algunos verbos comunes que encabezan ciertas expresiones como abrir o cerrar (la guardia), meter (el puño) o sacar (el brazo, el golpe): "El golpe lo "sacó" bien el campeón italiano y entró recto al rostro del español” ( $A B C$ 16-X-1965: 93) O algunos que indican la fuerza o intensidad del ataque al contrario como acorralar, desarbolar, castigar, martillear, machacar..., o los que indican los efectos inmediatos: tumbar, derribar, derrumbar, desmoronar: "...aunque anoche desmoronara a Evangelista tras someterle a un duro castigo..." (ABC 12-XI-1978: 39). Otros ensanchan el margen para apercibirse de la novedad, consistente en introducir el subcódigo del mundo animal, como cazar: "Puddu consiguió "cazar" a Velázquez con un tremendo "crochet" de izquierda" ( $A B C$ 30-I-1971: 63), o embestir para señalar la fuerza del ataque. Sugieren, en cambio, la defensa otros como 
refugiarse o encerrarse (en las cuerdas), agazaparse (detrás de sus puños) o enrocarse. Y no dejan de ser expresivos, aunque repetidos, el besar (la lona o el tapiz) y morder (el polvo) para anunciar el derribo, así como bailar (al contrario): "Legrá es rapidísimo en todo. Podría decirse que casi ni pisa el ring: baila sobre él, gira sobre el púgil de enfrente, le envuelve y le castiga en forma de aguijón" ( $A B C$ 25-VII-1968: 71). Y aun otros verbos como puntear, amagar con el puño: "el campeón europeo, después de puntear con el puño izquierdo, lanza un directo que llega al rostro del aspirante" ( $A B C$ 15-VIII-1971: 38) o flotar, que se dice cuando el púgil, bajo los efectos del castigo, no controla bien sus movimientos: “...puso en serios aprietos a Laguna, que "flotó" por el ring ante la lluvia de golpes del campeón" ( $A B C$ 15-IX-1971: 67). O clavar, por sorprender y dejar al contrario confuso un instante: "Paulino clavó a Hanser con un gancho de izquierda a la barbilla" (E 13-III-1927: 3).

La metáfora pone en relación dos términos que, en su interacción, crean un sentido autónomo que vale como experiencia de realidad, como un modo distinto de conocimiento o representación, eminentemente intuitivo y al margen de la verdad lógica. A la hora de hacer referencia a los golpes y a su continuidad y contundencia el foco de la metáfora se concentra unas veces en el verbo, como sucedía en todos los ejemplos anteriores, pero en otras pasa al sustantivo. Es fácil encontrar reiterada la expresión "lluvia de golpes" o parecidas estructuras de genitivo en que el primer término es "rociada", "vendaval", "torbellino"..., con lo que la imagen o término imaginario evoca el ámbito de la meteorología en sus efectos más violentos y como tal se asocia al término real "golpe". Con no menos frecuencia aparece la metáfora pura con sentido hiperbólico, a lo cual se presta mucho cualquier término del subcódigo bélico: "el campeón almacena mucha dinamita en sus guantes” ( $A B C$ 10-XI-1970: 69); “...en cuanto saca su torpedo de derecha, los rivales pasan a la posición horizontal" o, en la misma crónica, “comenzó el bombardeo por parte de Wilder..." $(M, 26-\text { II-2017 })^{11}$.

Cuando entra en juego la imaginación literaria, los hallazgos son imprevisibles, pues se busca, ante todo, la expresividad, la originalidad estilística, como sucede en las crónicas de reconocidos escritores como Miquelarena, que habla de "manos de plomo en guantes de crin" (1934: 50) o Alcántara: "sus manos eran dos pesas de plomo", que dice de Urtain, y también que "pega coces, trallazos de hondero entusiasta, descargas de bazooka", o, hablando de Legrá, que sus golpes "salen como pedradas de sus brazos delgados y fuertes como cables" (2014: 55 y 30). En otras ocasiones los golpes son "latigazos", "mazazos", "martillazos", "mandobles", "estocadas".., pues los brazos se usan como instrumentos muy variados de ataque o golpeo: "...hasta entonces solo había usado su "florete" de izquierda" ( $A B C$ 16-X-1965: 93), o estos dos símiles seguidos de Gilera: "suelta sus brazos como aspas de molino; su derecha la aplica a veces como látigo" ( $A B C$ 25-VII-1968: 71).

Las metáforas pueden aplicarse a cualquier realidad o circunstancia del combate. Por ejemplo, al mismo deporte se le parafrasea como "la ciencia del ring" o "el arte de las doce cuerdas" y, para señalar el lugar de la pelea, Miquelarena habla de "el pentagrama del ring” (1934: 58) y Alcántara de "cuartilla luminosa del ring” (2014: 56). Este mismo,

11 Esta creación de significados subjetivos a base de relacionar un término real con un campo de imágenes perteneciente a otro código: la meteorología, el bélico, etc. es propio de los enfoques cognitivos que inauguraron Lakoff y Johnson (1986). Y también, desde el enfoque funcional, un buen estudio aplicado al campo futbolístico lo llevó a cabo en este sentido Loureda Lamas (1997). 
refiriéndose a los boxeadores peleones, atacantes, dice que son "verdaderos bulldogs que no dan tregua y que no sueltan su presa" (2014: 26), y para hacerlo del que tiene coraje y no se da por vencido, habla de que "tiene corazón" o "superávit coronario" (2014: 35 y 68), figura esta que muy posiblemente tenga en cuenta la locución francesa il a du coeurs, con la que se expresa el coraje y la valentía de una persona. De forma elusiva alude a la cuenta del K.O como "la cuenta de los astronautas" (2014: 59). Cuando un púgil encaja mal los golpes en el mentón y sangra y es dañado fácilmente, se dice que tiene "mandíbula de cristal", calcándolo del inglés y el francés (glass jaw, ing.; menton en verre, fr.). Peculiar forma de referirse al momento culminante de una pelea, el K. O, es la que suele aparecer en una de las primeras crónicas de boxeo, que edulcora el sentido de ese momento dramático con otra imagen perifrástica: "Carpenter logró enviar al inglés al país de los sueños" (MD 11-XII-1913: 3). En un cronista imaginativo, que escapa de la expresión corriente y es proclive a la literatura, no escasean las sorpresas. Por hablar de uno en activo, mencionaremos, finalmente, algunas imágenes más encontradas en una sola crónica de Jorge Lera. Refiriéndose a los dos púgiles que protagonizaron una pelea memorable por su entrega y agresividad, los llama "dos titanes" y habla de su enfrentamiento como "locura de alto voltaje"; dice que uno de ellos "había sido alcanzado por un preciso hook de izquierda, un misil de cuarenta y cinco grados" y que, tiempo después, el otro "acabó el round con el piloto automático, hundido"; así como que al aspirante, cuando peor lo estaba pasando, le faltó experiencia para agarrarse y enfriar el combate" (EE, 23-VII-2016).

Pero volviendo al principio, al lenguaje más habitual y socorrido del boxeo, a la jerga compartida por boxeadores y entendidos, que cuenta con una larga acuñación, habría que referirse al nombre de ciertas categorías clasificatorias, cuyo segundo elemento, a modo de aposición atributiva, evoca una realidad imaginaria que tiene que ver con la ligereza del peso: mosca, gallo, pluma..., pues como comentó Gilera en su día: "Pero Legrá es un pluma por categoría y una pluma sobre el ring, porque así es de fino, de volátil". ( $A B C$ 25-VII-1968: 71). Y llevan también su carga metafórica otros nombres de golpes como los llamados gancho (hook, ing.; crochet, fr.), golpe de conejo (rabbit punch, ing.; coup de lapin, fr.) y sacacorchos (corkscrew, ing.; tire-bouchon, fr.) y otras expresiones que hacen referencia a distintas realidades y cuya conexión de significado no es difícil de deducir, pues el grado de aceptación popular es índice de lo acertado de su elección. Tal sería el caso de compuestos sintagmáticos como juego de piernas, juego de caderas, juego de las cuerdas ... También en el de denominaciones como coliflor a la oreja afectada por un derrame (cauliflower, ing.; oreille de chou-fleur, fr.); banderilla al efecto de la cura con agua oxigenada de la ceja abierta; castaña al golpe seco y preciso; picotazo a un golpe corto de jab, o pinchar a incordiar de continuo con el puño adelantado y apagón a la pérdida de reflejos por efectos de un golpe de ese tipo, contundente y bien colocado: "Alfredo Evangelista manifestó su asombro ante el golpe que produjo su "apagón”, manifestando que "no sabía que su oponente pegara tan duro"” (ABC 12-XI-1978: 39)... Del mismo modo que, compartido con otros deportes, se llama paquete al boxeador tosco, sin estilo; pegajoso al que se arrima mucho y busca el cuerpo a cuerpo; chichonera al casco de entrenamiento. Y se dice que uno está maduro cuando, ya muy castigado, solo precisa el golpe definitivo, o que hace la bicicleta: "Legrá hizo un primer asalto fulgurante, con sus "zogatas", su "bicicleta" y sus golpes aparatosos... (ABC 11-V-1968: 102).

\subsection{La metonimia}


No está tampoco ausente en la lengua pugilística la metonimia, otra figura que, como la metáfora, se incluye en el fenómeno retórico de los tropos. La metonimia procede, en lugar de por relación de semejanza entre las palabras, como la metáfora, por relación de contigüidad entre ellas. En la metáfora se da una interacción semántica de dos términos, uno real y otro imaginario, que comparten algunos semas; la metonimia, en cambio, sustituye el término real por otro con el que mantiene cierta relación referencial. Así, los guantes, objeto emblemático del boxeo, se erigen en representante de la práctica de este deporte y aparecen en determinadas ocasiones para denominar acciones muy concretas de sus usuarios: cruzar los guantes para aludir al combate o enfrentamiento entre los dos púgiles: “...el Consejo Mundial ha nombrado dos aspirantes: Pedro Carrasco y "Mando" Ramos, que en fecha próxima cruzarán los guantes" (ABC 15-XI-1971: 67), hacer guantes para referirse al entrenamiento, calzarse los guantes para anunciar su actividad y colgar los guantes para la retirada de la vida de competición. El objeto con el que se distingue a los campeones, el cinturón arcoiris, sirve también para representar el título que ganan u ostentan: "El campeón mosca de México tienen plena confianza de vencer al venezolano "Lumumba" y arrebatarle el cinturón universal" ( $A B C$ 9-XI-1976: 66). El símbolo de la victoria aparece otras veces representado por "la corona", "el cetro" o "el entorchado" mundial. Y el continente por el contenido hace acto de presencia al referirse a las ganancias dinerarias: "Carlos Monzón, campeón mundial absoluto de los pesos medios, dijo hoy que no tenía coraje para negarse a aceptar las bolsas fabulosas que le ofrecen por volver a boxear" ( $A B C$ 9-XI-1976: 66).

Al lugar del combate se le denomina, pensando en su forma, como cuadrilátero, y otras veces, pensando en el material de que está hecho, se habla de él como "el recinto de las doce cuerdas", o, en alusión a su suelo, aparece como la lona, en locuciones como "pisar la lona" y "arrojar a la lona", "tirar contra la lona", "caer en la lona" o "besar la lona". Y en recuerdo de los primeros tiempos, cuando los combates se celebraban al aire libre, en un prado, se habla de él como el tapiz: "En el segundo asalto envió a Rose al tapiz por la cuenta reglamentaria de ocho segundos" ( $A B C$ 8-XII-1968: 85), y remontándose a los combates de los circos romanos, como la arena: "José Manuel Ibar "Urtain”, campeón de Europa del peso pesado, se enfrentará a finales de mayo o principios de junio al dos veces campeón mundial Floyd Patterson en la arena principal del Madison Square Garden neoyorquino" (ABC 12-IV-1972: 69).

A la acción en sí del golpeo la sustituye el procedimiento y se habla de uno-dos: "A poco de iniciado el "match", un rápido uno-dos estuvo a punto de lanzar a la lona al francés", y en la misma crónica se recurre a la abstracción evitando lo concreto: "Se impuso con autoridad indiscutible el boxeador de color" ( $A B C$ 23-XII-1967: 77), como en esta otra: "Salcedo, con mejor esgrima, logró romper la entereza de Asensio" (ABC 7-X-1951: 48). Otras veces es la representación la que posterga al representante: "El título mundial para España. Lo consiguió Legrá en Porthcawl (Gales)" (ABC, 25-VII-1968, 71). Y, como es habitual en otras especialidades deportivas, también en el boxeo se juega con el lugar de procedencia para darle al deportista un denominación épica: "El puma de Baracoa", a Legrá, o "El potro de Vallecas" a Poli Díaz. Aún podrían añadirse algunos ejemplos más, pero valgan los aquí apuntados como habituales ejemplos de sustituciones metonímicas en este deporte.

$\mathrm{Al}$ estar basada en la sustitución, la metonimia es, junto con la elipsis, uno de los recursos que tiene la lengua para practicar la economía lingüística. Sin embargo, la metonimia no se queda como aquella solo en la restricción lingüística, sino que la aprovecha para dotar 
de relevancia al término superviviente o marcado, que se carga de expresividad. Por eso es, junto a la metáfora, un recurso dotado de especial significación expresiva, pues realza los significados y da lugar a una neología no denotativa, sino sugerente, estilística, con sus particulares efectos emotivos, épicos, sobre el lector u oyente. Es decir, que los dos principales procedimientos semánticos de creación neológica tienen, al margen de su interés lingüístico, una evidente función pragmática (Bobes, 2004; Sánchez Manzanares, 2009).

\section{LA INTEGRACIÓN EN LA LENGUA COMÚN}

La lengua del boxeo se ha ido formando en el tiempo y, tras más de un siglo de historia en el castellano, se puede decir que ya está plenamente asimilada en el sistema general de la lengua. Lo que en un principio eran neologismos, palabras nuevas que nombraban y representaban conceptos, objetos o situaciones desconocidos, ya están plenamente integrados en la lengua, aunque no siempre siguiendo los mismos mecanismos de adaptación. Así, por ejemplo, ring y round continúan apareciendo en las crónicas y en el habla de los aficionados y profesionales del deporte, alternando con sinónimos como cuadrilátero y asalto, y el punching ball y el punching bag se han convertido en balón y saco, preferentemente, aunque en los gimnasios aún haya quien los siga llamando punching. Muchos de estos anglicismos, y a veces galicismos, se han incorporado a la lengua de tal manera que han llegado a desarrollar toda una familia léxica, como en los casos de boxeo - boxear - boxeador - boxeril - boxistico; púgil - pugilato - pugilismo - pugilista - pugilístico; o nocaut - noquear - noqueo noqueador... Otros, incluso se han tornado polisémicos, de modo que a la denotación en el código de la lengua deportiva del boxeo añaden significados connotativos en otros códigos, como veremos más adelante, señales todas que muestran la plena adaptación en la lengua común y en el uso diario del español (Guerrero Ramos 1995: 13).

Haciendo un repaso por los principales diccionarios, es fácil comprobar el alto grado de integración y asunción del léxico del boxeo. El DRAE introdujo en 1936 las voces boxeo, púgil y pugilismo; en 1984 añadió croché, sonado y la nueva acepción que toma asalto en este deporte, antes solo reconocido para la esgrima; en 1992 fueron cuadrilátero, derechazo, gancho, grogui y lona las añadidas; en 2001, noquear y wélter. En la última actualización (versión electrónica 23.1), recoge ring y sparring y hace adaptaciones fonéticas y ortográficas de otras como mánager, réferi, nocaut, segundo y coquilla. También añade las nuevas acepciones que aporta este deporte en palabras como pegada, bolsa, gongo, fajarse y fajador. El DILE de María Moliner en su última versión recoge menos palabras que el anterior, pero sí algunas voces extranjeras que no están en él, como break, out, match y speaker (1995).

Los más receptivos a introducir términos boxísticos son los diccionarios más modernos o que se ocupan del español actual, tipo DEA (1999) y CLAVE (2006). A las palabras anteriores añaden bastantes más. En ambos aparecen round, punch, punching ball, sparring, footing y jab, entre los préstamo intactos. $D E A$, el más generoso en recoger el léxico de esta temática, incorpora ringside, clinch, sparring-partner, groggy, punching y puncheur, y aumenta las clases de golpes con un crochet sin adaptación más uppercut y swing. Y, entre adaptaciones y traducciones, introduce verbos como contragolpear, encajar y flotar; nombres caracterizadores como noqueador, pegador, fajador y esgrimista; golpes como contra, directo, derechazo e izquierdazo, y también vocablos como esquiva. Recoge también el nombre de los pesos, incluido el crucero, inexistente en DRAE y CLAVE, que sí nombraban 
a los otros. En CLAVE, que incluye algunos términos menos que el anterior, tienen, sin embargo, cabida algunas voces extranjeras nuevas como knock-out, $K O$, referee y avant match; recoge la doble forma sparring y esparrin, y adaptaciones como encajador ${ }^{12}$.

A ello, hay que añadir los grupos fraseológicos que tan ilustrativos se han hecho en la lengua común, como fuera de combate, contra las cuerdas, cuerpo a cuerpo, golpe bajo, peso pesado, bajar la guardia, colgar los guantes, tirar (arrojar, lanzar) la toalla (DRAE, $D E A$ y CLAVE); duro y a la cabeza (DRAE y DEA); golpe de conejo, golpe de suerte y salvar a alguien la campana (DRAE). Cantera y Gomis (2007) recogen muchos de los anteriores y añaden estar sonado, estar tocado y a la contra ${ }^{13}$.

Hay que concluir, pues, que el bagaje del léxico del boxeo incorporado a los diccionarios, como fruto de su uso en el habla común del castellano, es muy considerable, por lo que puede deducirse que, desde el punto de vista lingüístico, ha sido este un deporte muy productivo y aceptado. Lo corrobora su presencia continua en las crónicas periodísticas. Ejemplificaremos preferentemente con dos subcódigos muy aparentes, como son el político y el deportivo ${ }^{14}$, aunque se puede encontrar en cualquier otro:

Un "combate" de ideas en espacios públicos estará precedido por varios talleres en los grandes museos de la ciudad (El País 21-XI-1916).

Entre todas campea por lo insólito del ring "la riña del ascensor" de Génova, allá por enero de 2008, con Ruiz Gallardón a cuenta de quien iba o no en las listas de aquellas generales que Rajoy terminó perdiendo ( $A B C 5-\mathrm{V}-2015)$.

Cuando vienen mal dadas las cuentas públicas son un saco de golpes. Reciben lo suyo, también lo que empresas y familias ya no son capaces de encajar (El País 20-V-1913).

La banca admite que se enfrenta a una gran batalla comercial por no perder los buenos clientes, pero también debe esquivar otro golpe a su maltrecha reputación (El País 22-I-2017).

La candidata Clinton hubo de fajarse en el cuerpo a cuerpo de la zafiedad, intentando frenar a un buey en cacharrería (El País 16-XI-2016).

Una de cada tres mujeres sufre agresiones. España no debe bajar la guardia (El País 25XI-2016).

Le Pen noquea a Macron en la pugna por el voto obrero (La Razón 27-IV-2017).

Frente al llamamiento británico, Alemania e Italia consideraron que no sería prudente aprobar un nuevo castigo que pondría a Rusia contra las cuerdas antes incluso de la visita de Tillerson a Moscú ( $A B C$ 12-IV-2017).

Sánchez debió quedar (sic) tan grogui por la oferta que solo supo confirmarlo: "Entré en

12 Menos aceptación tienen estas voces en Alvar Ezquerra (NDVUA, 2003), que solo recoge en su sentido boxístico estricto punch, punch-ball y punching-ball, round, sparring, contragolpear y (peso) crucero, mientras que de ring, match y speaker da un sentido deportivo genérico. No aportan nada nuevo Neologismos del español actual (NEA) (2013) ni BOBNEO.

13 Muchos más términos y locuciones recogen Castañón Rodríguez y otros (2005), pero gran parte de ellos son genéricos y no exclusivos del boxeo. Más ajustado y preciso es García Molina (2002).

14 En este último es de gran interés de trabajo de Herráez Pindado (2011). 
Zarzuela sin un gobierno y ya tengo todos los ministros nombrados" (ABC 24-I-2016).

Hace un año no hubiera hecho falta. Pablo Iglesias es una suerte de sparring para Mariano Rajoy y nosotros queremos derrotar a Rajoy; son cosas bien distintas", diferenció Pedro Sánchez en un acto en Lleida (El País 1-V-2017).

La Generalitat tira la toalla ante la plaga de avispa asiática (El País 30-X-2016).

Intercambio de golpes. Maverick y Márquez se alternan en cabeza (Marca 22-IV-2017).

El club blanco lo considera un golpe bajo. La grave insinuación de Fernando Roig indigna a los árbitros y al Real Madrid (Marca 28-II-2017).

Repliegue, orden y contras. El Atleti se acerca a su mejor visión con una notable organización táctica (Marca 22-II-2017).

Hablando del Barcelona, revisión de objetivos en caso de K.O europeo (Marca 17-II-2017).

La pegada de Europa. El Real Madrid es el único equipo de las grandes ligas del continente que ha marcado en todos los partidos de esta temporada. (Marca 3-II-2017).

Aunque es un lenguaje muy asentado, tanto en las crónicas específicas como en la sociedad, sigue vivo y dinámico en el tiempo, como lo demuestra el empleo entre tradicional y creativo que hacen actualmente sus cronistas. No es difícil encontrar, junto a los nuevos despliegues metafóricos ya vistos de Jorge Lera, la innovación derivativa de Gistau en expresiones como "un nuevo escenario de golpiza" (ABC 4-V-2015: 63), "guanteando en un entrenamiento" ( $A B C$ 30-X-2014: 81) o atrevidos acortamientos: "se cuela para tirar voleas y uppers en corto" ( $A B C$ 27-I-2014: 45), y nuevas creaciones compuestas y locuciones: "En las grandes veladas del boxeo existe el concepto de combate escalón, que es aquel que no procura gloria pero conduce a peleas de mayor importancia" ( $A B C$ 23-VII2014: 12), "conservando, cuando logra fijar al rival, toda la potencia de sus series a dos alturas" (ABC 9-VI-2013: 115). Y aparecen anglicismos antes no usados, como el que este cronista repite en varios de sus artículos: "Con su táctica rope a dope apoyándose en las cuerdas para contragolpear, acabaría noqueando a Foreman" ( $A B C$ 5-VI-2016: 20), o este otro sacado de Jorge Lera: "es rápido de piernas y manos, intuitivo y con un gran sentido de la distancia y de la anticipación, lo que algunos llaman 'timing"” (EE 10-VIII-2016)

Lo que ya es más dudoso es que, dada la reserva actual contra este deporte y el ostracismo al que últimamente está sometido en la mayoría de los medios de comunicación, estos nuevos hallazgos y usos lingüísticos lleguen a repercutir en el habla de la calle, como de hecho sucedió con la preferencia y entusiasta acogida de hace medio siglo.

\section{CONCLUSIÓN}

El deporte del boxeo penetró en España a finales del siglo XIX y en la tercera década del siglo XX se puede decir que era ya un deporte asentado, que tenía sus aficionados, y al que los periódicos dedicaban atención, por lo que en torno a él fue cuajando una lengua específica. Sería, sin embargo, en los años sesenta y setenta del siglo cuando, bien visto y 
apoyado por el régimen franquista, llegó a su apogeo. En la democracia, en cambio, fue postergado, pues se le tildó de deporte violento y movido por turbios intereses.

A pesar de la polémica que siempre lo acompañó, incluso cuando era más popular, lo cierto es que el léxico del boxeo ha tenido una destacada incidencia en la lengua común y ha sido uno de los deportes, con el fútbol, que más palabras y locuciones ha aportado a la vida cotidiana. La expresividad de su léxico hace que, con frecuencia, las palabras más características de su acervo sirvan para referirse, en sentido figurado, a distintas situaciones ordinarias, destacando los ámbitos de la política y de otros deportes.

Como nuevo espectáculo de ocio introducido en España, en torno a él se fraguó todo un lenguaje por los procedimientos lingüísticos más diversos. Los iniciales neologismos extranjeros -ingleses y franceses- fueron bien aceptándose sin más o adaptándose, bien traduciéndose o calcándose, hasta constituir en las crónicas periodísticas, en los gimnasios y en la calle, el código particular, específico, que hoy es. De manera normal y sucesiva se ha valido de los diversos procedimientos neológicos para desarrollar su caudal léxico y expresivo. Unos han sido puramente léxicos, como los préstamos extranjeros puros; otros han sido morfológicos, a través de la derivación o de la composición univerbal o sintagmática; otros, sintáctico-semánticos, como las locuciones y demás fraseología y los cambios de categoría gramatical por elipsis. Finalmente, los procedimientos estrictamente semánticos le han dotado a este lenguaje de una especial expresividad y creatividad, gracias a las metáforas y metonimias.

Dado el importante papel del deporte en la sociedad actual, no es, pues, de extrañar, el alto grado de desarrollo e integración que esta lengua específica ha alcanzado en el sistema lingüístico general del castellano.

\section{CORPUS DOCUMENTAL}

$(A B C)$ Hemeroteca $A B C$ (1903-2017). Incluye $(A B C$, And.) la edición andaluza y $(B y N)$ Blanco y Negro (1891-2000). hemeroteca.abc.es.

(MD) Hemeroteca El Mundo Deportivo (1906-1999). www.mundodeportivo.com/hemeroteca.

(E) Excelsior (1927). htpp://www.liburuklik.euskadi.net/

(LR) La Razón (2017)

(M) Marca (2017)

$(E P)$ http://elpais.com/archivo/

(EE) http://www.elespanol.com/hemeroteca/2016/

\section{BIBLIOGRAFÍA}

Agulló, R. (2003). Diccionario Espasa términos deportivos. Madrid: Espasa Calpe.

Alcántara, M. (2014). La edad de oro del boxeo. 15 asaltos de leyenda, (León Gross, T. y Rivera, A., eds.). Madrid: Libros K.O.

Alfaro, R. J. (1970). Diccionario de anglicismos. Madrid: Gredos.

Almela, R. (1999). Procedimientos de formación de palabras en español. Barcelona: Ariel. 
Alvar Ezquerra, M. (2003). (NDVUA) Nuevo diccionario de voces de uso actual. Madrid: Arco/Libros. $8^{\mathrm{a}}$ ed.

(2012). La formación de palabras en español, $8^{\mathrm{a}}$ ed. Madrid: Arco Libros.

Bobes, C. (2004). La metáfora. Madrid: Gredos.

Bosque, I. (2001). "Sobre el concepto de 'colocación' y sus límites". LEA, 1, pp. 9-40.

Bordonaba Zabalza, C. (2009). "Neología y formación de palabras". En Calvi, M. V. et al., Las lenguas de especialidad en español. Roma: Carocci editore, pp. 39-54.

Cabré, M. T. (1993): La terminología. Teoría, metodología, aplicaciones. Barcelona: Antártida/Empúries.

Cantera Ortiz de Urbina, J. y Gomis Blanco, P. (2007): Diccionario de fraseología española. Madrid: Abada Editores.

Carbonero Cano, P. (1979). "Léxico autónomo procedente de combinatoria léxica". Estudios Paraguayos, $7 / 1$, pp. 177-185.

Cardells Martí, F. y Gener Galbís, C. (2004). "Historia, lenguaje y hecho deportivo: consideraciones a propósito del boxeo", Comunicación y Estudios Universitarios, 12, pp. 41-50.

Casado Velarde, M. (2015). La innovación léxica en el español actual. Madrid: Síntesis.

Casares, J. (1950). Introducción a la lexicografía moderna, Revista de Filología Española, Anejo LII de la R.A.E.

Castañón Rodríguez, J. (1993). El lenguaje periodístico del fútbol. Valladolid: Secretariado de Publicaciones de la Universidad.

- (2004). Diccionario terminológico del deporte. Gijón: Trea.

Castañón Rodríguez, J., Loza Olave, E. y García Molina, E. T. (2005). Términos deportivos en el habla cotidiana. Logroño: Universidad de La Rioja.

(Clave) (2012). Diccionario CLAVE . Madrid: SM: http://clave.smdiccionarios.com/app.php

Cebrián Boné, J. L. (dir) (1989). La gran enciclopedia de los deportes olímpicos, 3. Barcelona: Ediciones del Drac.

Corpas Pastor, G. (1996). Manual de fraseología española. Madrid: Gredos.

Curell Aguilá, C. (2009). Diccionario de galicismos del español peninsular contemporáneo. Strasbourg: Éditions de Linguistique et Philologie.

Falcinelli, A. (2007). "Valores y funciones del sufijo -AZO en el español actual y sus equivalencias en italiano". Linguae, 1, pp. 23-52.

Fernández García, A. (1972). Anglicismos en el español (1891-1936). Oviedo.

García Molina, E. T. (2002). Deporte y lenguaje. Madrid: Consejo Superior de Deportes.

García-Page Sánchez, M. (2008). Introducción a la fraseología española. Estudio de las locuciones. Barcelona: Anthropos.

García Turza, C. et al. (coords.) (1994). El español en el lenguaje deportivo. Madrid: Fundación EFE. Gómez Capuz, J. (2005). La inmigración léxica. Madrid: Arco Libros.

Guerrero Ramos, G (1995). Neologismos en el español actual. Madrid: Arco/Libros.

- (1999). “¿Tecnolectos, lenguajes (lenguas) específicos, especiales, especializados o de especialidad?", Lingüística para el siglo XXI: III Congreso organizado por el Departamento de Lengua Española. Salamanca: Universidad de Salamanca, pp. 879-888.

Guerrero Salazar, S. y Cremades García, R. (coords.) (2012). El lenguaje deportivo en los medios de comunicación. Madrid: VG Ediciones.

Hernández Alonso, N. (2003). El lenguaje de las crónicas deportivas. Madrid: Cátedra.

Herráez Pindado, A. J. (2002). La lengua del ciclismo en francés: análisis semántico y lexicográfico. Madrid: Universidad Complutense, Facultad de Filología (sprints.ucm.es/4684/)

(2011). "El vocabulario del boxeo como fuente de metáforas violentas en el deporte". En Sanz Gil, M. y Verdegal Cerezo, J. M., Construcción de identidades y cultura del debate en los estudios de lengua francesa. Castelló de la Plana: Publicaciones Universitat Jaume I, pp. 217-227.

Lakoff, G. y Johnson, M. (1986). Las metáforas de la vida cotidiana. Madrid: Cátedra. 
Lang, M. F. (1992). Formación de palabras en español. Madrid: Cátedra.

Lerat, P. (1997). Las lenguas especializadas. Barcelona: Ariel.

Lorenzo, E. (1996). Anglicismos hispánicos. Madrid: Gredos.

Loureda Lamas, O. (1997). "Hacia la caracterización de la función de la metáfora en el lenguaje del fútbol”. Lenguaje y textos, 10, pp. 185-212.

Loza Olave, E. y Castañón Rodríguez, J. (2010): Términos deportivos de origen extranjero, Logroño: Universidad de La Rioja.

Miquelarena, J. (1934). Stadium (Notas de sport). Madrid: Espasa Calpe.

Moliner, M. (1995). (DUE) Diccionario de uso del español: www.buscadoor.com/diccionario-mariamoliner/.

Monge, F. (1972). "Sufijos españoles para la designación de 'golpe'”. Homenaje a Francisco Ynduráin, 2. Zaragoza: Facultad de Filosofía y Letras, pp. 229-247.

Oliva Marañón, C. (2012). "Lenguaje deportivo y comunicación social: prototipo coetáneo de masas", Revista de Comunicación de la SEECI, Año XV / 28.

Osorio Olave, G. y Serra Sepúlveda, S. (2012). "Colocaciones, compuestos sintagmáticos y locuciones nominales: hacia un intento de delimitación conceptual”. Lenguas Modernas, 39 (primer semestre), pp. 103-116.

Paredes Duarte, $\mathrm{M}^{\mathrm{a}}$. J. (2009). Perspectivas semánticas de la elipsis. Madrid: Arco/Libros.

RAE. (DRAE) Diccionario de la R.A.E / http://dle.rae.es

RAE y AALE (2009). (NGLE) Nueva gramática de la lengua española, Morfología. Sintaxis I. Madrid: Espasa.

Rodríguez Díez, B. (1981). Las lenguas especiales. El léxico del ciclismo. León: Colegio Universitario de León.

Rodríguez Feu, F. (1987). El boxeo como deporte y profesión. Barcelona: Hispano Europea.

Rodríguez González, S. (2013). "Pseudoanglicismos en español actual. Revisión crítica y tratamiento lexicográfico", Revista Española de Lingüistica, 43/1, pp. 123-169.

Rodríguez-Piñero Alcalá, A. I. y García Antuña, M. (2009). "Lenguas de especialidad y lenguas para fines específicos: precisiones terminológicas y conceptuales e implicaciones didácticas". En Vera Luján, A. y Martínez Martínez, I., El español en contextos especificos: enseñanza e investigación. XX Congreso Internacional de la Asociación para la Enseñanza del español como Lengua Extranjera (ASELE), vol II. Fundación Comillas.

Sánchez García, R. (2009). "Boxeo y proceso de civilización en la sociedad española". Apunts Educación Física y Deportes, 96, pp. 5-13.

Sánchez Manzanares, Mª C. (2009). "Funciones pragmáticas de la metonimia”, Tonos Digital, XVII.

Santiago Lacuesta, R. y otros (1999). "La derivación nominal". En RAE, Gramática descriptiva de la Lengua Española, (Bosque, I. y Demonte, V., dir.). Madrid: Espasa.

Seco, M., Andrés, O. y Ramos, G. (2011). (DEA) Diccionario del español actual. Madrid: Santillana.

Tenorio, I. C. (2005). "Las formas de composición nominal en español y sus denominaciones". Lenguaje, 33, pp. 379-404.

Teruel Sáez, A. (2006). Contribución al estudio del lenguaje del fútbol en la prensa escrita española, tesis doctoral. Madrid: UNED.

Ullmann, S. (1972). Semántica. Madrid: Aguilar.

Viada, A. (1903). Manual de sport. Madrid: Adrián Romo editor, pp. 685-705. 
